\title{
Risks of injury in youth rugby - what are the issues?
}

A paediatric neurosurgeon wrote an opinion piece for the British Medical Journal on the unknown risks of youth rugby. ${ }^{[1]}$ He explained at the start of the article that he was entitled to an opinion, having spent time 'picking skull fragments out of the contused frontal lobes of a teenage rugby player'. He was also writing in his capacity as a 'rugby parent', having watched the game at close quarters.

He made a couple of key points: that 'schools, coaches, and parents all contribute to a tribal, gladiatorial culture that encourages excessive aggression, suppresses injury reporting, and encourages players to carry on when injured'; and that although schools require risk assessments for seemingly low-risk activities, every Saturday rugby teams of children face each other with the risk of incurring serious injuries. He stated: 'fractures, dislocations, ligamentous disruptions, and dental and maxillofacial injuries are common'.

In the article, he made several points about reducing the risk of youth rugby injury, summarised here in point form:

- creative match scheduling

- pre- and early season strength and conditioning programmes

- considering weight rather than age categories

- having policies to reduce early return-to-play after concussive injuries

- training for proper tackle technique from a young age

- consideration for non-contested scrums

- meticulous refereeing, with zero tolerance for dangerous practices

- non-contact options (e.g. touch rugby) as an introduction to contact rugby.

His concluding comment that 'schools, clubs, medical facilities, and, most importantly, regulatory bodies cooperate now to quantify the risks of junior rugby' elicited reactions from several quarters. Support came from a paediatric consultant, a clinical neurophysiologist, an orthopaedic and trauma surgeon, a general practitioner and a parent, who took the time to write letters to the journal. All had various points to add, but basically supported the thrust of the editorial. Researchers from the University of Edinburgh and Bath University also responded with letters, pointing out that, in fact, much is being done with injury surveillance, research and law changes to reduce the risk of injury. While agreeing with the sentiment of reducing the risk of injury in youth rugby, the researchers pointed out that the editorial failed to represent the positive steps that are currently in place.

This type of discussion always prompts an examination of the facts. Closer to home, the BokSmart National Rugby Safety and injury prevention Programme ${ }^{[2]}$ was forced to examine its fundamental principles and operating procedures. The BokSmart programme has an extensive body of information published on their website (www. boksmart.com), which addresses many of the points listed in the editorial. For example, the pros and cons of age-group v. weight-based categories are presented. The importance of periodisation and strength and conditioning are discussed, and detailed guidelines are provided for players of various ages. Extensive guidelines about return to play after injury are also presented. As part of the programme, referees are engaged about safety, particularly the laws governing dangerous play - all referees have to be certified before they are able to referee a match. Coaches have to undergo training on safety techniques (particularly for scrumming and tackling). The South African Rugby Union has also legislated that coaches have to be BokSmart certified before they are allowed to coach. BokSmart has a comprehensive injury tracking programme for youth tournaments, ${ }^{[3,4]}$ and an extensive database that keeps track of catastrophic injuries. ${ }^{[5]} \mathrm{A}$ series of events are triggered as soon as a player, anywhere in the country, sustains a serious injury. Research to examine the mechanisms of injury, ${ }^{[6]}$ the cost of injuries ${ }^{[7]}$ and the efficacy of injury prevention programmes ${ }^{[8]}$ is ongoing.

Injuries are inevitable in any contact sport, particularly a sport such as rugby in which collisions between players running at high speed is a fundamental part of the game. It is important to be critical about how the game is managed to ensure that high-risk situations are eradicated. It is also important to have valid data about the risks of injury, so that participants and, in the case of young players - parents, can make informed choices about whether they want their children to participate. However, credit should be given where credit is due, and in most countries where rugby is a popular sport, much is being done to satisfy these points. Finally, it should be acknowledged that even though the number of catastrophic injuries are decreasing in junior rugby, ${ }^{[8]}$ one catastrophic injury per year is one injury too many; the effect such an injury has on the individual and the family and friends of that person is ghastly. Until such time as these injuries are eradicated, there is much to do.

\section{Mike Lambert}

Editor-in-chief

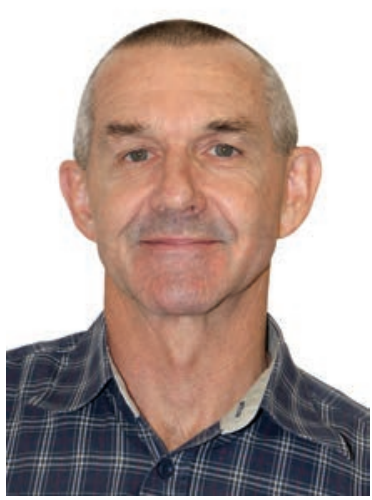

\section{S Afr J Sports Med 2015;27(1):2. DOI:10.7196/SAJSM.616}

\section{References}

1. Carter M. The unknown risks of youth rugby. BMJ 2015;350:h26. [http://dx.doi org $/ 10.1136 / \mathrm{bmj} . \mathrm{h} 26$

2. Viljoen W, Patricios J. BokSmart - implementing a National Rugby Safety Programme. Br J Sports Med 2012;46(10):692-693. [http://dx.doi.org/10.1136/ bjsports-2012-091278]

3. Brown J, Verhagen E, Viljoen W, et al. The incidence and severity of injuries at the 2011 South African Rugby Union (SARU) Youth Week tournaments. S Afr J Sport Med 2012;24(2):49-54.

4. Burger N, Lambert MI, Viljoen W, Brown JC, Readhead C, Hendricks S. Tacklerelated injury rates and nature of injuries in South African Youth Week tournament rugby union players (under-13 to under-18): An observational cohort study. BMJ Open 2014;4(8):e005556. [http://dx.doi.org/10.1136/bmjopen-2014-005556]

5. Brown JC, Lambert MI, Verhagen E, Readhead C, van Mechelen W, Viljoen W. The incidence of rugby-related catastrophic injuries (including cardiac events) in South Africa from 2008 to 2011: A cohort study. BMJ Open 2013;3(2):e002475. [http:// dx.doi.org/10.1136/bmjopen-2012-002475]

6. Hendricks S, Lambert MI, Brown JC, Readhead C, Viljoen W. An evidence-driven approach to scrum law modifications in amateur rugby played in South Africa. Br J Sports Med 2014. [http://dx.doi.org/10.1136/bjsports-2013-092877]

7. Brown JC, Viljoen W, Lambert MI, et al. The economic burden of time-loss injuries to youth players participating in week-long rugby union tournaments. J Sci Med Sport 2014 (in press). [http://dx.doi.org/ 10.1016/j.jsams.2014.06.015]

8. Brown JC, Verhagen E, Knol D, van Mechelen W, Lambert MI. The effectiveness of the nationwide BokSmart rugby injury prevention program on catastrophic injury rates. Scand J Med Sci Sports 2015 (in press). [http://dx.doi.org/10.1111/sms.12414] 